\title{
Medial Sural Artery Perforator Free Flap: Legitimate Use as a Solution for the Ipsilateral Distal Lower Extremity Defect
}

\author{
Geoffrey G. Hallock, MD ${ }^{1}$ \\ ${ }^{1}$ Division of Plastic Surgery, Sacred Heart and The Lehigh Valley \\ Hospitals, Allentown, Pennsylvania, St. Luke's Hospital, Bethlehem, \\ Pennsylvania \\ J Reconstr Microsurg 2014;30:187-192.
}

\begin{abstract}
Address for correspondence Geoffrey G. Hallock, MD, Division of Plastic Surgery, Lehigh Valley Hospitals, 1230 South Cedar Crest Boulevard, Suite 306, Allentown, PA 18103

(e-mail: gghallock@hotmail.com).
\end{abstract}

\begin{abstract}
The medial sural artery perforator (MSAP) flap captures the cutaneous territory of the medial calf, and can potentially be advantageous as a thin free flap, even in the most obese individual, for coverage of most foot and/or ankle defects where bulk is a liability. The anatomy is fairly constant, as usually at least one reasonably large perforator can always be found emanating from the medial head of the gastrocnemius muscle. As a microsurgical tissue transfer, a long vascular pedicle of large caliber is routinely possible which facilitates any requisite microanastomoses.

Over the past decade from our free flap registry, 14 patients with distal lower extremity wounds were covered specifically with a perforator flap based on the ipsilateral medial sural artery; out of which only $2(14 \%)$ were females.

In this series using a MSAP free flap, there was only one failure requiring salvage by a different free flap. All but one case was a sequel of trauma, and these involved all zones of the foot and ankle. A skin graft of the donor site was necessary in $5 / 14(36 \%)$ patients. In no cases did the flap subsequently impede the use of shoes nor hinder ambulation.

\section{Keywords}

- medial sural artery perforator free flap

- microvascular surgery

- lower extremity

- foot and ankle The study concluded the major disadvantage of the MSAP flap is the nonaesthetic scar left at the donor site which can be quite conspicuous, especially if a skin graft had to be used. Yet even this detriment can be acceptable for ipsilateral distal lower extremity defects where reconstruction of the defect itself may be cosmetically unappealing. This may be the best indication for the MSAP flap to be considered first as the free flap of choice.
\end{abstract}

The possibility of use of the integument of the medial calf as a free flap donor site based on musculocutaneous branches of the medial sural vessels was first investigated in cadaver dissections by Taylor and Daniel. ${ }^{1}$ Montegut and Allen ${ }^{2}$ presented this at a regional meeting as a local flap alternative to the gastrocnemius myocutaneous flap. At the 5th International Course on Perforator Flaps in Gent, Belgium (2001), the anatomical basis of the requisite perforators to the medial sural artery flap was given as a free paper, ${ }^{3}$

received

March 23, 2013

accepted after revision

August 22, 2013

published online

October 10, 2013 immediately followed by Cavadas et al explaining their clinical series in using this as a free flap. ${ }^{4}$ Since then, these original anatomical findings have been verified, ${ }^{5-8}$ and clinical applications as a thin perforator flap have run the gamut throughout the body proving versatility in the head and neck $\mathrm{k}^{9,10}$ to the distal extremities, $, 5,9,11-14$ indeed headto-toe. In a podium discussion at the session for use of perforator flaps for the lower extremity at the 6th Conference of the World Society for Reconstructive Microsurgery
Copyright $\odot 2014$ by Thieme Medical Publishers, Inc., 333 Seventh Avenue, New York, NY 10001, USA. Tel: +1(212) 584-4662.
DOI http://dx.doi.org/ 10.1055/s-0033-1357276. ISSN 0743-684X. 
Table 1 Medial sural artery perforator flap characteristics

\begin{tabular}{|l|l|l|l|l|l|l|l|}
\hline Name & Etiology & $\begin{array}{l}\text { Location } \\
\text { defect }^{\mathrm{a}}\end{array}$ & Size $\mathbf{( c m )}$ & Perforators & Donor site & $\begin{array}{l}\text { Recipient } \\
\text { vessels }\end{array}$ & Complications \\
\hline JA & MCA-heel degloving & 5 & $5 \times 8$ & 1 & Scar & PT & \\
\hline AB & Fall: fibula fx & 6 & $3 \times 10$ & 2 & Scar & AT & \\
\hline BC & Crush-great toe amp & 1 & $6 \times 17$ & 1 & Skin graft & DP & \\
\hline JE & Fall: distal tibia $\mathrm{fx}$ & 6 & $5 \times 15$ & 3 & Skin graft & PT & Chimeric; patient died \\
\hline JF & Fall: pylon $\mathrm{fx}$ & 6 & $3 \times 7$ & 1 & Scar & PT & \\
\hline DK & Fall: calcaneal fx & 5 & $5.5 \times 10$ & 2 & Skin graft & AT & $\begin{array}{l}\text { Venous congestion; } \\
\text { 2nd free flap salvage }\end{array}$ \\
\hline MM & Fall: achilles avulsion $\mathrm{fx}$ & 5 & $4.5 \times 12$ & 1 & Scar & PT & $\begin{array}{l}\text { Dehiscence donor } \\
\text { site closure }\end{array}$ \\
\hline SN & Fall: pylon $\mathrm{fx}$ & 6 & $3 \times 5$ & 1 & Scar & PT & \\
\hline EO & Club foot- unstable scar & 5 & $6 \times 11$ & 1 & Skin graft & PT & \\
\hline RS & Fall: calcaneal $\mathrm{fx}$ & 5 & $4 \times 11$ & 2 & Scar & AT & \\
\hline AS & Fall: calcaneal $\mathrm{fx}$ & 5 & $3 \times 8$ & 2 & Scar & AT & \\
\hline GV & Fall: distal tibial $\mathrm{fx}$ & 6 & $3 \times 7$ & 2 & Skin graft & PT & \\
\hline JW & ATV: great toe avulsion & $1 / 3$ & $4 \times 13$ & 1 & Scar & DP & $\begin{array}{l}\text { Lateral sural perforator } \\
\text { anomaly }\end{array}$ \\
\hline RW & Fall: distal fibula fx & 6 & $3 \times 11$ & 2 & Scar & AT & \\
\hline
\end{tabular}

Abbreviations: AT, anterior tibial; ATV, all-terrain vehicle accident; fx, fracture; DP, dorsalis pedis; MCA, motor cycle accident; PT, posterior tibial. a Zone of distal lower leg or foot (-Fig. 1).

in Helsinki, Finland (2011), ${ }^{15}$ many observers on the contrary took exception and vociferously opposed use of this donor site for any part of the body without exception; as the disfigurement at the donor site even if closed primarily to leave just a linear scar on the calf, much less if skin grafted, was generally unacceptable but even more so as an aesthetic defect for women. It was pointed out that a superficial circumflex iliac perforator flap ${ }^{16}$ or medial circumflex femoral artery perforator flap ${ }^{17}$ could achieve the same purpose, while leaving a defect in the lateral or medial groin, respectively, which could easily be hidden by normal clothing. This moderator suggested a counterargument in that if used for the ipsilateral distal lower extremity where there would ultimately be an aesthetic deformity at the defect site anyway, the attributes of this flap could outweigh this disadvantage. ${ }^{15}$ Therefore, for this specific indication, consideration of the use of the medial sural artery perforator (MSAP) flap as a free flap would be legitimate, as to be discussed here in more detail.

\section{Methods and Materials}

A retrospective review of our free flap registry over the past decade found 14 patients with distal lower extremity wounds who had had a perforator flap using the cutaneous territory of the ipsilateral medial sural artery ( - Table 1). Only two (14\%) were females. In all cases but one, the defect requiring coverage was a sequel of some form of trauma, and essentially these involved all zones of the foot and ankle ( - Fig. 1) where a thin flap was essential to permit use of everyday shoe wear.

\section{Surgical Technique}

Preoperative planning first requires identification of a desirable perforator of the posterior calf overlying the medial gastrocnemius muscle. Wang et $\mathrm{a}^{5}$ suggest that a perforator will be found within a circle of radius $4 \mathrm{~cm}$ that is centered at the intersection of a line drawn from the medial epicondyle of the femur and prominence of the lateral malleolus, and a second line drawn from the midpoint of the popliteal crease to the medial malleolus, which thereby will take into account variability in height of the individual. The latter line roughly corresponds to the course of the medial sural artery, and according to Kim et al, ${ }^{6}$ a second perforator may sometimes be found within $7 \mathrm{~cm}$ distal to the first. Unfortunately, these are only rough guidelines as variation here is $\operatorname{common}^{18}$; and, unless computed tomography angiography or color duplex ultrasound $^{7}$ is available, the ubiquitous handheld acoustic Doppler by default may be a reasonable substitute for widely scanning this region ${ }^{19}$ for a perforator of choice.

A template of the defect should be eccentrically placed with about two-thirds of the design distal to the chosen perforator to allow a longer pedicle, if needed. The major axis of the design should parallel the tibial border to best capture adjacent perforasomes if a longer flap is needed. ${ }^{20}$ The entire procedure can be performed within a bloodless field by using a tourniquet, but without previous exsanguination to ensure that venous structures remain filled and highly visible. Note that calf perforators tend to course obliquely for some distance after leaving the heads of the gastrocnemius before piercing the deep fascia, presumably to safely adjust for muscle contraction during ambulation. 


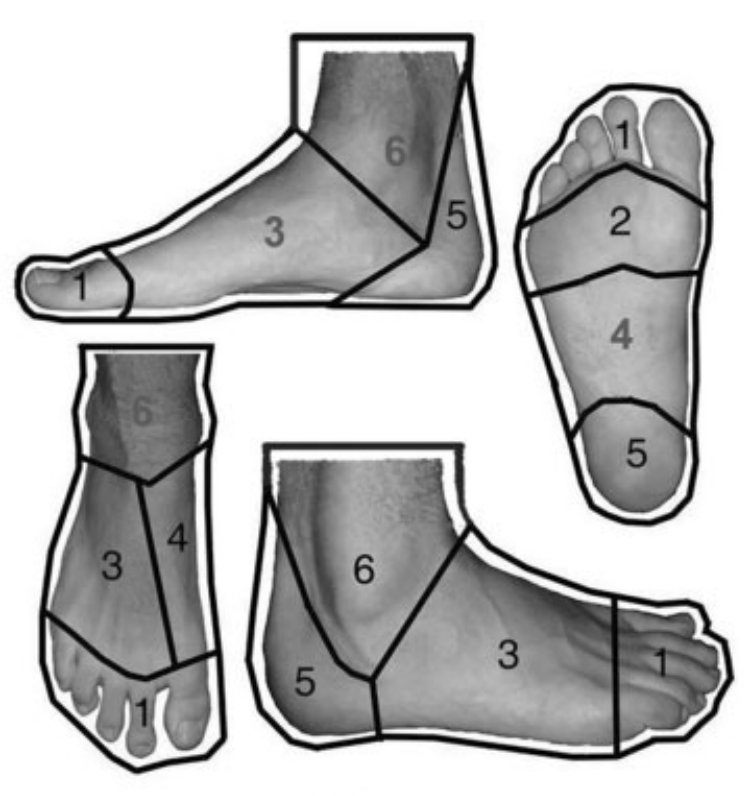

Fig. 1 Zones of the distal lower extremity including foot and ankle. ${ }^{22}$ Zone 1, distal foot and toes; zone 2, plantar forefoot; zone 3, dorsal foot; zone 4, midfoot; zone 5, hind foot; and zone 6, distal leg and ankle.

Therefore, after incising only the anterior border of the MSAP flap through the subcutaneous tissues, a subfacial dissection may be the safest approach to first confirm the exact location of the perforator. Often, the actual site of facial perforation is different than suspected, so the design must be correspondingly altered. Next, the usual tedious intramuscular dissection of these relatively diminutive perforators back to a branch of the medial sural vessels must be completed until the desired pedicle length and/or vessel caliber is obtained. Any motor nerves encountered are carefully protected. The posterior boundary can then be incised through the deep fascia to create an island flap. At the superior flap margin, a large subcutaneous vein, if encountered, should be kept to permit flap venous supercharging later if needed, although this maneuver is rarely required. The tourniquet is next deflated and flap perfusion assessed. If adequate, transfer to the recipient defect with the requisite microanastomosis is performed per routine. Donor site closure requires a skin graft if primary closure is too tight to avoid an iatrogenic compartment syndrome. ${ }^{21}$

\section{Results}

All MSAP flaps in this series were for ipsilateral traumatic defects except for one unstable surgical scar ( - Table 1 ), with the majority (86\%) involving men. Most were used for the distal leg and ankle or hind foot zones according to the Duke classification (-Fig. 1). ${ }^{22}$ One patient had a chimeric flap including a portion of the medial gastrocnemius muscle for fill of a bony defect. ${ }^{23,24}$ The flap lived, but the patient succumbed from congestive heart failure in the immediate postoperative period. One flap was lost in a diabetic patient with a calcaneal fracture, secondary to venous congestion, which had to be salvaged with a different free flap, for an overall success rate of $92.9 \%$.

A single perforator was utilized in $7 / 14$ (50\%) of flaps, with more only if they lined up along the same medial sural branch during the dissection of the flap pedicle, and if each seemed particularly diminutive. The largest flap was $17 \mathrm{~cm}$ in length and well served by a single perforator. In one case, the only perforator found over the medial head of the gastrocnemius muscle actually crossed the midline and emanated from the lateral head, so technically this was a lateral sural artery perforator flap. Lateral ankle and foot, plus some Achilles defects required the anterior tibial vessels as the recipient site. Some Achilles and all medial ankle defects used the closer posterior tibial vessels. Forefoot or toe defects used the dorsalis pedis artery and a subcutaneous vein as the recipient vessels. Regardless of the recipient artery, in all cases an endto-side anastomosis was performed, with end-to-end venous anastomoses.

A skin graft was necessary for 5/14(36\%) of the donor sites, and usually only if flap width were greater than $5 \mathrm{~cm}$, although in one obese male a $3 \mathrm{~cm}$ wide flap required a skin graft so as to avoid excessive tension during skin approximation. A linear scar was left for both female patients.

\section{Case Example: Zone 5-Posterior Hind Foot}

Patient MM lost his balance while cleaning his truck and sustained a closed left Achilles tendon avulsion fracture. Reinsertion was performed by suturing the tendon to screw anchors in his comminuted calcaneus. The surgical wound never healed and became infected, requiring that all foreign material be removed some 6 months after the accident. During this same time period he had been treated at a local wound center with no progress. The Achilles tendon remained exposed (-Fig. 2), but there was by this time no evidence of osteomyelitis. Therefore, a $4.5 \mathrm{~cm} \times 12 \mathrm{~cm}$ MSAP free flap from the ipsilateral calf was raised based on a single perforator. The posterior tibial vessels were the recipient site. The primary donor site closure dehisced slightly, but healed with conservative treatment only. He returned to work 2 months later fitting easily into his normal steel-tipped reinforced work boots without further difficulty.

\section{Case Example: Zone 6-Distal Leg and Ankle}

Patient AB fell down her basement steps sustaining a closed bimalleolar left ankle fracture. The lateral ankle incision used for plate fixation of her fibula never really healed, with hardware exposure occurring 11 weeks after this surgery (-Fig. 3). The plate was removed leaving the fibula exposed. Local tissues were extremely indurated and unsuitable to be used for bony coverage. For this narrow wound, a gracilis muscle free flap was considered. Instead, a $3 \mathrm{~cm} \times 10 \mathrm{~cm}$ MSAP free flap from the ipsilateral calf was raised based on 2 perforators that serendipitously entered opposite ends of the flap to insure complete flap perfusion. The anterior tibial vessels were the recipient site. The donor site could be closed 

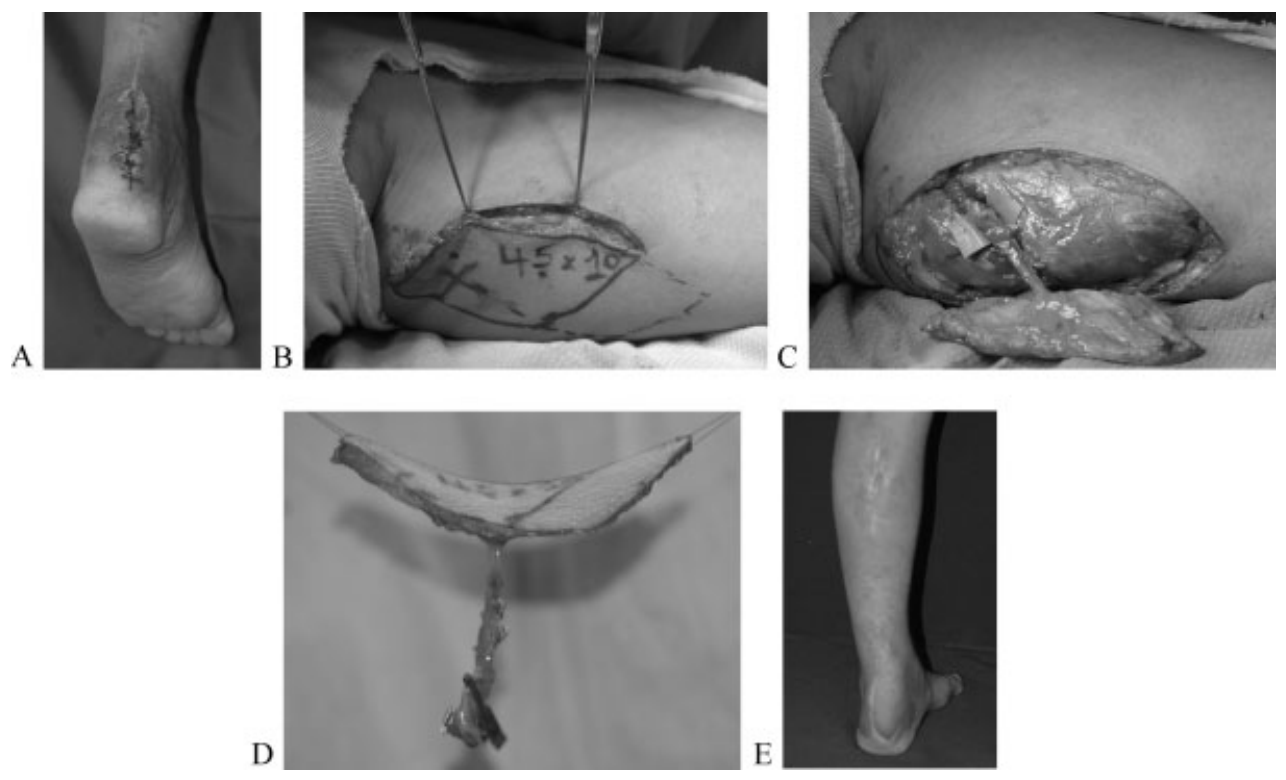

Fig. 2 Patient MM. (A) Exposed left Achilles tendon, (B) original median sural artery perforator (MSAP) flap design (solid line) on ipsilateral medial calf about perforator " $x$ " heard with audible Doppler, but following anterior exploratory incision with exact perforator identification, was moved slightly distally (dotted line), (C) island MSAP flap in situ with microgrid under vascular pedicle in trough created by division of medial gastrocnemius muscle fibers, showing how superficial the vascular supply can be, (D) the free MSAP flap based on a single perforator, (E) healed heel with widened donor site scar of ipsilateral calf.
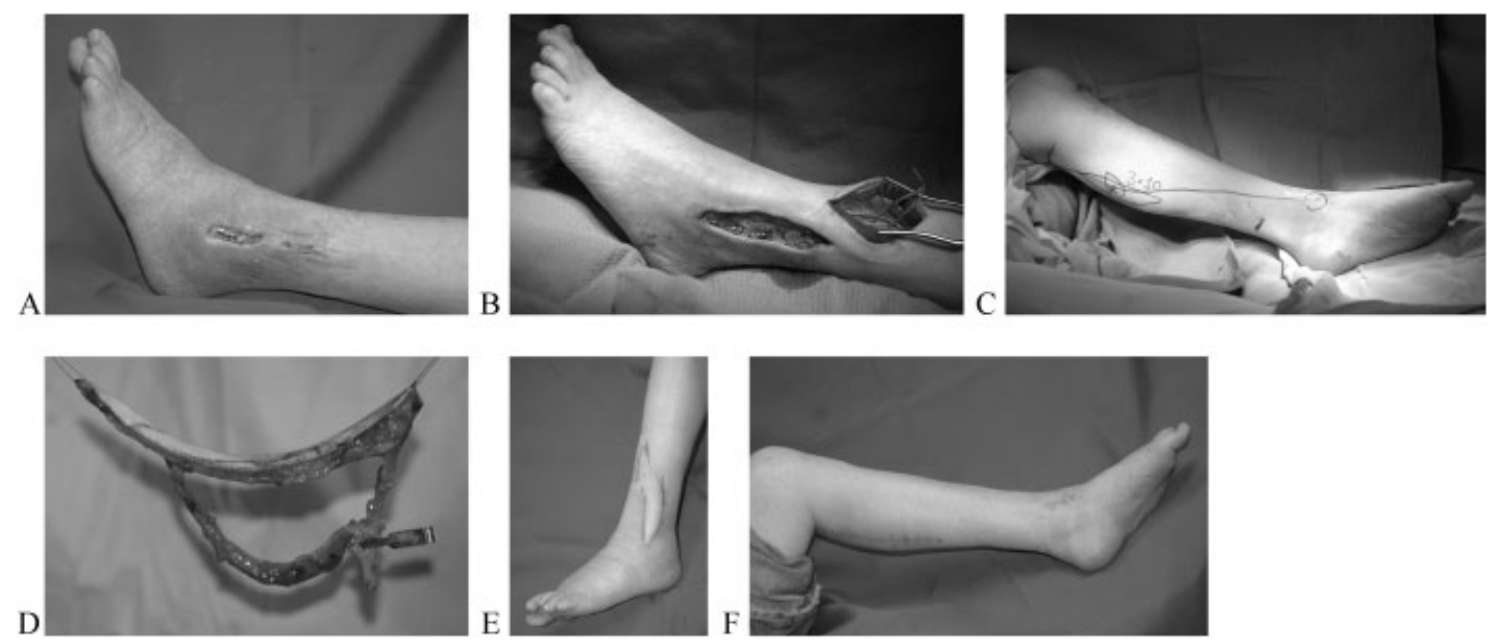

Fig. 3 Patient AB. (A) Exposed left fibula fracture fixation plate, (B) following plate removal, bone remains exposed. Note nearby anterior tibial recipient site. (C) Flap designed longitudinally about perforator " $x$ " heard with audible Doppler, that was found along line drawn from midpoint of the popliteal crease to the prominence of the medial malleolus, (D) free medial sural artery perforator (MSAP) flap with two perforators emanating from the same branch of the medial sural vessels fortuitously at opposite ends of the flap, (E) healed MSAP flap 2 months later, (F) linear scar of medial calf donor site.

primarily. After 2 months, the appearance of the left lower leg was superior to a skin grafted muscle free flap.

\section{Discussion}

The MSAP flap usually relies on musculocutaneous perforators of the medial head of the gastrocnemius muscle; and the existence of at least one of adequate size is normally present, ${ }^{3,7,8}$ although none were found in one case in this series, albeit an alternative was nearby. Pedicle caliber is sufficient for patulous microanastomoses, with the artery up to $2 \mathrm{~mm}$ and vein $4 \mathrm{~mm}$ in diameter. ${ }^{13}$ Pedicle length in our anatomical dissections had a mean of $15.3 \mathrm{~cm},{ }^{3}$ and clinically can easily exceed $10 \mathrm{~cm}^{9,13}$ to allow reach to a recipient site well above the ankle (-Fig. $\mathbf{3}$ ); so as to avoid the need for vein grafts and yet still be outside the zone of injury of a given foot defect. This characteristic also avoids sacrifice of a major artery to the foot, where often circulation already is compromised. The MSAP flap is relatively thin even in the obese individual, ${ }^{25}$ which is important for foot and ankle defects where motion during ambulation and use of shoe wear cannot be impeded. Flap harvest can be done with the patient 
in either a supine or prone position. ${ }^{25}$ A tourniquet may be used to create a bloodless field to facilitate dissection. The course of perforators from the medial sural branches tend to run longitudinally very close to the posterior surface of the muscle $^{3}$ (-Fig. 2), so that pedicle dissection is simplified compared with other major perforator flap donor sites. Spinal anesthesia alone may be satisfactory for patients with other comorbidities. Chimeric flaps including vascularized plantaris tendon or gastrocnemius muscle can simultaneously be transferred independently. ${ }^{23}$ Of course, as with all perforator flaps, there is minimal muscle damage so that function is maximally preserved.

The MSAP perforators are relatively diminutive so that great care must be observed during their dissection, but this should not be beyond the ability of the usual microsurgeon. However, the other major disadvantage may be an insurmountable obstacle. That is the residue left at the donor site. Even a linear scar, much less a skin graft, is understandably highly objectionable especially for women, as this is not easily hidden by clothing. When the MSAP flap is chosen for head and neck or upper extremity problems, this would then be inappropriate as long as other better alternatives are available. ${ }^{16,17}$ Yet one could legitimately argue that for the ipsilateral lower extremity where a thin free flap is necessary that can be easily and rapidly harvested, that a MSAP flap is a reasonable alternative. All dissection is within the same field. All eventual residue will be close together, so that the scarring inevitable and obvious at the recipient site may be little different or perhaps worse than that of the MSAP calf donor site itself. Even in a woman, an adjacent linear scar may be better than having another body region violated. That decision must be understood and approved by the patient before embarking on whatever course is needed to provide lower limb salvage. The MSAP flap provides here another justifiable alternative.

\section{Acknowledgments}

This article was presented in-part at the DUKE 9th Annual Fresh Cadaver Flap Dissection Course for Reconstructive Surgery, Durham, North Carolina, August 6, 2011, and at the 14th International Course on Perforator Flaps, Seoul, Korea, October 16, 2011. The author thank assistance from David C. Rice, BS, Physician Extender, Sacred Heart Hospital, Allentown, and St. Luke's Hospital, Bethlehem, Pennsylvania, for extending help with all aspects of microsurgery.

\section{References}

1 Taylor GI, Daniel RK. The anatomy of several free flap donor sites. Plast Reconstr Surg 1975;56(3):243-253

2 Montegut WJ, Allen RJ. Sural artery perforator flap as an alternative for the gastrocnemius myocutaneous flap. Presented at: The 90th Annual Scientific Assembly of the Southern Medical Association; November 20-24, 1996; Baltimore, MD

3 Hallock GG. Anatomic basis of the gastrocnemius perforator-based flap. Ann Plast Surg 2001;47(5):517-522

4 Cavadas PC, Sanz-Giménez-Rico JR, Gutierrez-de la Cámara A, Navarro-Monzonís A, Soler-Nomdedeu S, Martínez-Soriano F.
The medial sural artery perforator free flap. Plast Reconstr Surg 2001;108(6):1609-1615, discussion 1616-1617

5 Wang X, Mei J, Pan J, Chen H, Zhang W, Tang M. Reconstruction of distal limb defects with the free medial sural artery perforator flap. Plast Reconstr Surg 2013;131(1):95-105

$6 \mathrm{Kim} \mathrm{HH}$, Jeong JH, Seul JH, Cho BC. New design and identification of the medial sural perforator flap: an anatomical study and its clinical applications. Plast Reconstr Surg 2006;117(5):1609-1618

7 Kosutic D, Pejkovic B, Anderhuber F, et al. Complete mapping of lateral and medial sural artery perforators: anatomical study with Duplex-Doppler ultrasound correlation. J Plast Reconstr Aesthet Surg 2012;65(11):1530-1536

8 Wong MZ, Wong CH, Tan BK, Chew KY, Tay SC. Surgical anatomy of the medial sural artery perforator flap. J Reconstr Microsurg 2012; 28(8):555-560

9 Xie XT, Chai YM. Medial sural artery perforator flap. Ann Plast Surg 2012;68(1):105-110

10 Kao HK, Chang KP, Chen YA, Wei FC, Cheng MH. Anatomical basis and versatile application of the free medial sural artery perforator flap for head and neck reconstruction. Plast Reconstr Surg 2010; 125(4):1135-1145

11 Chen SL, Chen TM, Lee CH. Free medial sural artery perforator flap for resurfacing distal limb defects. J Trauma 2005;58(2):323-327

12 Lin CH, Lin CH, Lin YT, Hsu CC, Ng TW, Wei FC. The medial sural artery perforator flap: a versatile donor site for hand reconstruction. J Trauma 2011;70(3):736-743

13 Chen SL, Chuang CJ, Chou TD, Chen TM, Wang HJ. Free medial sural artery perforator flap for ankle and foot reconstruction. Ann Plast Surg 2005;54(1):39-43

14 Kim ES, Hwang JH, Kim KS, Lee SY. Plantar reconstruction using the medial sural artery perforator free flap. Ann Plast Surg 2009;62(6): 679-684

15 Hallock GG. Perforator flaps to the extremities. Presented at: 6th Conference of the World Society for Reconstructive Microsurgery; July 1, 2011; Helsinki, Finland

16 Koshima I, Nanba Y, Tsutsui T, et al. Superficial circumflex iliac artery perforator flap for reconstruction of limb defects. Plast Reconstr Surg 2004;113(1):233-240

17 Hallock GG. Further experience with the medial circumflex femoral(GRACILIS) perforator free flap. J Reconstr Microsurg 2004; 20(2):115-122

18 Hallock GG. A primer of schematics to facilitate the design of the preferred muscle perforator flaps. Plast Reconstr Surg 2009; 123(3):1107-1115

19 Hallock GG. Attributes and shortcomings of acoustic Doppler sonography in identifying perforators for flaps from the lower extremity. J Reconstr Microsurg 2009;25(6):377-381

20 Saint-Cyr M, Wong C, Schaverien M, Mojallal A, Rohrich RJ. The perforasome theory: vascular anatomy and clinical implications. Plast Reconstr Surg 2009;124(5):1529-1544

21 Addison PD, Lannon D, Neligan PC. Compartment syndrome after closure of the anterolateral thigh flap donor site: a report of two cases. Ann Plast Surg 2008;60(6):635-638

22 Hollenbeck ST, Woo S, Komatsu I, Erdmann D, Zenn MR, Levin LS. Longitudinal outcomes and application of the subunit principle to 165 foot and ankle free tissue transfers. Plast Reconstr Surg 2010; 125(3):924-934

23 Sano K, Hallock GG, Hamazaki M, Daicyo Y. The perforator-based conjoint (chimeric) medial sural (medial gastrocnemius) free flap. Ann Plast Surg 2004;53(6):588-592

24 Sano K, Hallock GG, Rice DC. Sural artery perforator flap. In: Blondeel PN, Morris SF, Hallock GG, Neligan PC, ed. Perforator Flaps: Anatomy, Technique, \& Clinical Applications. 2nd ed. St. Louis: Quality Medical Publishing; 2013:803-816

25 Hallock GG, Sano K. The medial sural medial gastrocnemius perforator free flap: an 'ideal' prone position skin flap. Ann Plast Surg 2004;52(2):184-187 